\title{
High-Performance Ga2O3 Diode Based on Tin Oxide Schottky Contact
}

DOI:

10.1109/LED.2019.2893633

\section{Document Version}

Accepted author manuscript

Link to publication record in Manchester Research Explorer

\section{Citation for published version (APA):}

Du, L., Xin, Q., Xu, M., Liu, Y., Mu, W., Yan, S., Wang, X., Xin, G., Jia, Z., Tao, X., \& Song, A. (2019). HighPerformance Ga2O3 Diode Based on Tin Oxide Schottky Contact. IEEE Electron Device Letters, 1-1. https://doi.org/10.1109/LED.2019.2893633

\section{Published in:}

IEEE Electron Device Letters

\section{Citing this paper}

Please note that where the full-text provided on Manchester Research Explorer is the Author Accepted Manuscript or Proof version this may differ from the final Published version. If citing, it is advised that you check and use the publisher's definitive version.

\section{General rights}

Copyright and moral rights for the publications made accessible in the Research Explorer are retained by the authors and/or other copyright owners and it is a condition of accessing publications that users recognise and abide by the legal requirements associated with these rights.

\section{Takedown policy}

If you believe that this document breaches copyright please refer to the University of Manchester's Takedown Procedures [http://man.ac.uk/04Y6Bo] or contact uml.scholarlycommunications@manchester.ac.uk providing relevant details, so we can investigate your claim.

\section{OPEN ACCESS}




\title{
High-Performance $\mathrm{Ga}_{2} \mathrm{O}_{3}$ Diode Based on Tin Oxide Schottky Contact
}

\author{
Lulu Du, Qian Xin, Mingsheng Xu, Yaxuan Liu, Wenxiang Mu, Shiqi Yan, Xinyu Wang, Gongming \\ Xin, Zhitai Jia, Xu-Tang Tao, Aimin Song, senior Member, IEEE
}

\begin{abstract}
A high-performance Schottky diode based on a 600- $\mu$ m-thick $\mathrm{Cr}$-doped $\mathrm{\beta}_{-} \mathrm{Ga}_{2} \mathrm{O}_{3}$ single crystal has been fabricated using $\mathrm{SnO}_{\mathrm{x}}$ as the Schottky contact. The $\mathrm{SnO}_{\mathrm{x}}$ film was deposited in argon/oxygen mixture gas to ensure an oxygen-rich stoichiometry in $\mathrm{Ga}_{2} \mathrm{O}_{3}$ near the Schottky interface, thus reducing oxygen deficiency related interface state density. The $\mathrm{SnO}_{\mathbf{x}}$ film included three components: $\mathrm{Sn}, \mathrm{SnO}$, and $\mathrm{SnO}_{2}$, as revealed by $X$-ray photoelectron spectroscopy characterization. The high quality $\mathrm{Ga}_{2} \mathrm{O}_{3}$ single crystal grown by an edge-defined film-fed method has a carrier concentration of $1.0 \times 10^{18} \mathrm{~cm}^{-3}$ and an electron mobility of $\sim 90 \mathrm{~cm}^{2} / \mathrm{Vs}$. Current density-voltage characteristics of the Schottky diode demonstrated high performance with a large barrier height of $1.17 \mathrm{eV}$, a close-to-unity ideality factor of 1.02 , and a high rectification ratio beyond $10^{10}$. Frequency-dependent capacitance and conductance analysis revealed that the maximum active interface state density is $5.92 \times 10^{13}$ at a frequency of $7 \mathrm{kHz}$.
\end{abstract}

Index Terms- $\mathrm{Ga}_{2} \mathrm{O}_{3}$, Schottky barrier diodes (SBDs), tin oxide $\left(\mathrm{SnO}_{\mathrm{x}}\right)$.

\section{INTRODUCTION}

$\mathrm{G}$ ALLIUM oxide, $\mathrm{Ga}_{2} \mathrm{O}_{3}$, has attracted extensive attention for the next generation power electronics and solar-blind optoelectronics due to its large breakdown electric field strength of $8 \mathrm{MV} / \mathrm{cm}$ and extremely wide bandgap of 4.5-4.9 $\mathrm{eV}$ [1]-[6]. Schottky contact quality is critical for Schottky diode power electronics, because it determines their key performances such as breakdown voltage, leakage current, and

This work was supported by the National Key Research and Development Program of China (Grant No. 2016YFB0406502, 2016YFA0301200, and 2016YFA0201800), Engineering and Physical Sciences Research Council (EPSRC) (Grant No. EP/N021258/1), the Natural Science Foundation of China(61504044), the Natural Science Foundation of Shandong Province (ZR2018MF029 and ZR201709260014), the Key Research and Development Program of Shandong Province (2017GGX10111, 2017GGX10121 and 2018GGX101027), China Postdoctoral Science Foundation funded project (2016M590634), and the Fundamental Research Funds of Shandong University (2018JC037, 2018WLJH87, 2017TB0021, 2016WLJH44, and 2015WLJH36).

L. Du, Q. Xin, M. Xu, Y. Liu, S. Yan, and A. Song are with Center of Nanoelectronics, and School of Microelectronics, Shandong University, Jinan 250100, P. R. China (e-mail: xinq@sdu.edu.cn, mshxu@163.com).

L. Du, Q. Xin, M. Xu, Y. Liu, W. Mu, S. Yan, Z. Jia, X. Tao, and A. Song are with State Key Laboratory of Crystal Materials, Shandong University, Jinan 250100, P. R. China (e-mail: z.jia@sdu.edu.cn, txt@sdu.edu.cn).

$\mathrm{X}$. Wang is with Institute of Thermal Science and Technology, Shandong University, Jinan 250061, P. R. China

G. Xin is with School of Energy and Power Engineering, Shandong University, Jinan 250061, P. R. China

A. Song is with School of Electrical and Electronic Engineering, University of Manchester, Manchester M13 9PL, United Kingdom. rectification ratio, $I_{\text {on/off }}$ [7]-[13]. Recently, many efforts have been made to improve $\mathrm{Ga}_{2} \mathrm{O}_{3}$ Schottky contact quality [7]-[11]. Konishi et al. demonstrated that fluorine ion treatment can realize a barrier height, $\Phi_{\mathrm{B}}$, increase of $0.3 \mathrm{eV}$ of $\mathrm{Ga}_{2} \mathrm{O}_{3}$ Schottky barrier diodes, SBDs [9]. Sasaki et al. developed MOS-type $\mathrm{Ga}_{2} \mathrm{O}_{3}$ SBDs with improved $\Phi_{\mathrm{B}}$ of $1.07 \mathrm{eV}$ but a slight deteriorated ideality factor, $n$ [10]. Most of the reported $\mathrm{Ga}_{2} \mathrm{O}_{3}$ Schottky contacts used high work function metals such as $\mathrm{Pt}, \mathrm{Pd}, \mathrm{Ni}$, and $\mathrm{Au}$, for achieving large $\Phi_{\mathrm{B}}$ [6], [7], [9], [10], [12], [13]. To the best of our knowledge, only Müller et al. demonstrated oxidized noble metal $\mathrm{PtO}_{\mathrm{x}}$ as $\mathrm{Ga}_{2} \mathrm{O}_{3}$ Schottky contacts, and the diodes showed an extremely large $\Phi_{\mathrm{B}}$ of 1.94 $\mathrm{eV}$, an ideal $n$ of 1.09 , and a high $I_{\mathrm{on} / \text { off }}$ of $4.5 \times 10^{9}$ at $\pm 2 \mathrm{~V}$ [11]. For $\mathrm{ZnO}$ and InGaZnO SBDs, it has been demonstrated that a series of oxides such as $\mathrm{AgO}_{x}$ [14], $\mathrm{PtO}_{x}$ [15], $\mathrm{PdO}_{x}$ [16], and Ru-Si-O [17], [18], at Schottky interfaces can improve the Schottky contact quality due to reduction of oxygen deficiency related interface state density by ensuring oxygen-rich stoichiometry near the Schottky interface [14]-[18].

In contrast to the high work function metals such as Pt, Pd, $\mathrm{Au}, \mathrm{Ni}$, etc. which are usually expensive, $\mathrm{Sn}$ has a low work function and is inexpensive. In this work, we used reactively sputtered $\mathrm{SnO}_{\mathrm{x}}$ as Schottky contacts to achieve high performance $\mathrm{Ga}_{2} \mathrm{O}_{3}$ SBD, providing a new effective way to fabricate high quality Schottky contact on $\mathrm{Ga}_{2} \mathrm{O}_{3}$.

\section{Experimental Details}

Cr-doped $\beta-\mathrm{Ga}_{2} \mathrm{O}_{3}$ single crystal was grown by edge-defined film-fed growth method, and the (100)-oriented $\beta-\mathrm{Ga}_{2} \mathrm{O}_{3}$ plate with a thickness of $\sim 600 \mu \mathrm{m}$ and a size of $2 \mathrm{~mm} \times 10 \mathrm{~mm}$ was obtained by cleaving the bulk single crystal. To form cathode ohmic contact, firstly, one surface of the cleaved $\mathrm{Ga}_{2} \mathrm{O}_{3}$ plate was etched with inductively coupled plasma (ICP) technique using a mixture gas of $\mathrm{BCl}_{3}(15 \mathrm{sccm})$ and $\mathrm{Ar}(5 \mathrm{sccm})$ for 2 min under the ICP/RF power of $150 \mathrm{~W} / 15 \mathrm{~W}$ and a chamber pressure of $10 \mathrm{mTorr}$. Then, $\mathrm{Ti} / \mathrm{Au}(40 \mathrm{~nm} / 20 \mathrm{~nm})$ was deposited by e-beam evaporation onto the etched $\mathrm{Ga}_{2} \mathrm{O}_{3}$ plate surface, and a rapid thermal annealing in $\mathrm{N}_{2}$ gas at $350{ }^{\circ} \mathrm{C}$ for 2 min was applied followed for improving the ohmic contact. A 200-nm-thick $\mathrm{SnO}_{\mathrm{x}}$ layer was deposited by reactive sputtering using a pure $\mathrm{Sn}$ target $(99.9 \%, 3$ inch in diameter) at room temperature with a sputtering power of $50 \mathrm{~W}$. The working pressure and oxygen partial pressure, $P_{\mathrm{O}}$, during the sputtering were $\sim 5.7$ mTorr and $3.1 \%$, respectively. Finally, the $\mathrm{SnO}_{\mathrm{x}}$ film was capped with an e-beam evaporated Ti layer. The active area of the SBD is $7.1 \times 10^{-4} \mathrm{~cm}^{2}$. 
The surface morphology and roughness of the $\mathrm{Ga}_{2} \mathrm{O}_{3}$ plate were analyzed by an atomic force microscope (AFM, Dimension FastScan ${ }^{\mathrm{TM}}$ ). The cross-sectional structure of $\mathrm{Ti} / \mathrm{SnO}_{\mathrm{x}} / \mathrm{Ga}_{2} \mathrm{O}_{3}$ was analyzed using a scanning electron microscope (SEM, FEI Nova 450). The microstructure of the $\mathrm{Ga}_{2} \mathrm{O}_{3}$ plate was elucidated by a Raman spectrometer (Renishaw in Via-Reflex) using a 532-nm wavelength laser at a power of $5 \mathrm{~mW}$. The chemical composition of the $\mathrm{SnO}_{\mathrm{x}}$ film was characterized by X-ray photoelectron spectroscopy (XPS, ESCALAB 250Xi). The binding energy was calibrated by setting the $\mathrm{C} 1 \mathrm{~s}$ signal at $284.6 \mathrm{eV}$. The current density-voltage, $J-V$, and capacitance-voltage, $C-V$, characteristics were measured using a semiconductor analyzer (Agilent 2902B) and an LCR meter (Agilent E4980A), respectively, at room temperature in dark.

\section{RESULTS AND DISCUSSION}

The $\mathrm{Ga}_{2} \mathrm{O}_{3}$ exhibits high transmittance and a clear absorption edge at $\sim 260 \mathrm{~nm}$, as shown in Fig. 1(a), corresponding to a band gap of $\sim 4.8 \mathrm{eV}$. AFM analysis indicates that the cleaved $\mathrm{Ga}_{2} \mathrm{O}_{3}$ surface is atomically flat with a root mean square roughness of $0.3 \mathrm{~nm}$ in an area of $1 \times 1 \mu \mathrm{m}^{2}$, as shown in the inset of Fig. 1(a). The $\mathrm{Ga}_{2} \mathrm{O}_{3}$ plate shows ten sharp and narrow Raman active peaks located at 113, 146, 171, 201, 346, 418, 477, 630, 659, and $768 \mathrm{~cm}^{-1}$, as shown in Fig. 1(b), illustrating high crystallinity of the plate. The peak at $201 \mathrm{~cm}^{-1}$ correlates to the characteristic vibration and translation mode of $\mathrm{Ga}-\mathrm{O}$ chains [19]. The peaks between 300 and $500 \mathrm{~cm}^{-1}$ relate to deformation of $\mathrm{Ga} 2 \mathrm{O} 6$ octahedra [20], and the peaks between 600 and $800 \mathrm{~cm}^{-1}$ attribute to the stretching and bending of $\mathrm{GaO} 4$ tetrahedra [20].

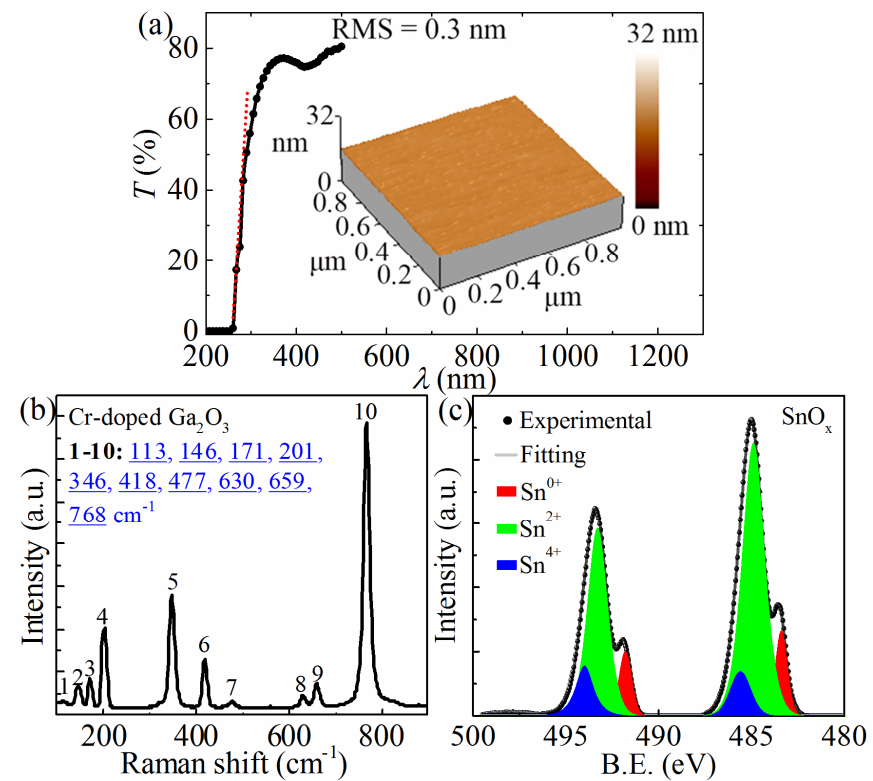

Fig. 1. Figure R1. UV-visible transmission spectrum (a) and Raman spectrum (b) of the $\mathrm{Ga}_{2} \mathrm{O}_{3}$ single crystal. (c) XPS of $\mathrm{Sn} 3 \mathrm{~d}$ for the $\mathrm{SnO}_{\mathrm{x}}$ film. Inset: AFM image of the $\mathrm{Ga}_{2} \mathrm{O}_{3}$ flake surface with root mean square surface roughness.

To determine the composition of the $\mathrm{SnO}_{\mathrm{x}}$ film, an XPS measurement was carried, with the topmost native oxidized $\mathrm{SnO}_{2}$ layer on the $\mathrm{SnO}_{\mathrm{x}}$ film was sputtered away by low energy
(3 keV) argon plasma bombardments to get rid of its contribution. The XPS results illustrate that three compositions of $\mathrm{Sn}, \mathrm{SnO}$, and $\mathrm{SnO}_{2}$ are included in the film, and the predominant composition is SnO. Figure 1(c) shows the $\mathrm{Sn}$ $3 \mathrm{~d}_{5 / 2}$ and $3 \mathrm{~d}_{3 / 2}$ spectra of with deconvoluted fittings (Gaussian + Lorentz $(<30 \%)$ ). The binding energy of the $\mathrm{Sn} 3 \mathrm{~d}_{5 / 2}$ and $3 \mathrm{~d}_{3 / 2}$ peaks centered at 484.4 and $492.8,485.9$ and 494.3 , and 486.6 and $495.0 \mathrm{eV}$, corresponding to $\mathrm{Sn}^{0+}, \mathrm{Sn}^{2+}$, and $\mathrm{Sn}^{4+}$, respectively [21]. (a)

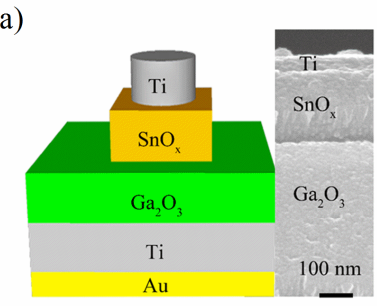

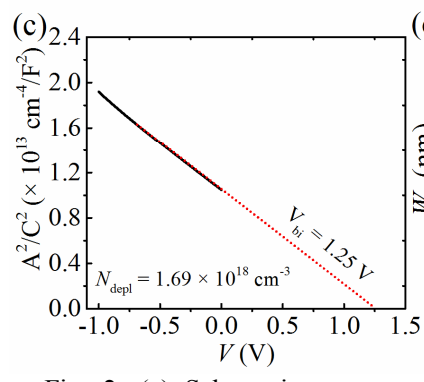
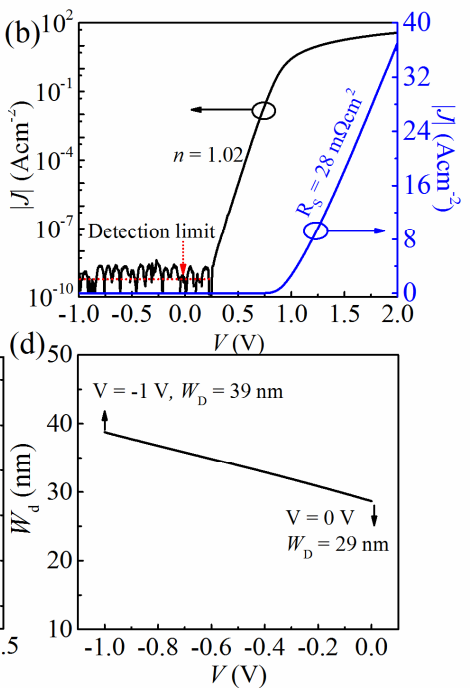

Fig. 2. (a) Schematic structure of the diode and SEM image of the cross-sectional structure of $\mathrm{Ti} / \mathrm{SnO}_{\mathrm{x}} / \mathrm{Ga}_{2} \mathrm{O}_{3}$. (b) Semi-logarithmic and linear plots of a $\mathrm{SnO}_{\mathrm{x}} / \beta-\mathrm{Ga}_{2} \mathrm{O}_{3} \mathrm{SBD} . \mathrm{A}^{2} / C^{2}$ (c) and width of the space charge region (d) in dependence on the applied voltage.

The morphology and electrical properties of the $\mathrm{SnO}_{\mathrm{x}} / \mathrm{Ga}_{2} \mathrm{O}_{3}$ SBD were investigated. Figure 2(a) shows the SEM image of the cross-sectional structure of $\mathrm{Ti} / \mathrm{SnO}_{\mathrm{x}} / \mathrm{Ga}_{2} \mathrm{O}_{3}$, which shows two clear and smooth interfaces: $\mathrm{SnO}_{\mathrm{x}} / \mathrm{Ga}_{2} \mathrm{O}_{3}$ and $\mathrm{Ti} / \mathrm{SnO}_{\mathrm{x}}$. Using the Richardson constant of $41.1 \mathrm{Acm}^{-2} \mathrm{~K}^{-2}$ for $\beta-\mathrm{Ga}_{2} \mathrm{O}_{3}$ [3], [22], by fitting the forward $J-V$ curve in Fig. 2(b) with the thermionic emission theory [23], the $n$ and $\Phi_{\mathrm{B} . J V}$ of the SBD are extracted as 1.02 and $1.17 \mathrm{eV}$, respectively. Here, the $\Phi_{\mathrm{B} . J V}$ is defined as the $\Phi_{\mathrm{B}}$ extracted by the $J-V$ curve. The close-to-unity $n$ indicates a very high quality Schottky interface between $\mathrm{Ga}_{2} \mathrm{O}_{3}$ and $\mathrm{SnO}_{\mathrm{x}}$. Such high performance is mainly due to that the main composition $\mathrm{SnO}$ in the $\mathrm{SnO}_{\mathrm{x}}$ film usually contains a high density of tin vacancy defect states [24], [25]. Such tin vacancies induce oxygen dangling bonds which can compensate for oxygen vacancies in $\mathrm{Ga}_{2} \mathrm{O}_{3}$ at the Schottky interface. Thus, an insulating interfacial $\mathrm{Ga}_{2} \mathrm{O}_{3}$ layer with high oxygen stoichiometry at the $\mathrm{SnO}_{\mathrm{x}} / \mathrm{Ga}_{2} \mathrm{O}_{3}$ interface can be formed, leading to the large barrier height and near unity ideality factor. The ideality of the contact was further supported by the very low reverse current below our detection limit. The forward-bias current at $V>0.9 \mathrm{~V}$ is limited by the series resistance, $R_{\mathrm{s}}$, of $\sim 28 \mathrm{~m} \Omega \cdot \mathrm{cm}^{2}$ extracted from the slope of the $J-V$ curve in linear scale in Fig. 2(b). The $R_{\mathrm{S}}$ of the SBD is lager than the resistance of the $\mathrm{Ga}_{2} \mathrm{O}_{3}$ layer, which is $4.2 \mathrm{~m} \Omega \mathrm{cm}^{2}$ given by $R=L / q n \mu_{n}$ [23]. Here, $L$ is the thickness of the $\mathrm{Ga}_{2} \mathrm{O}_{3}$, $\mu_{\mathrm{n}}$ is the mobility and is $90 \mathrm{~cm}^{2} / \mathrm{Vs}$ extracted by Hall effect measurement, and $n$ is the carrier concentration and is $1.0 \times$ 
$10^{18} \mathrm{~cm}^{-3}$ extracted by Hall effect measurement. The large $R_{\mathrm{S}}$ of SBD is contributed by the resistance of the insulating interfacial $\mathrm{Ga}_{2} \mathrm{O}_{3}$ layer. The SBD shows high performances such as a high $I_{\text {on/off }}$ of $>10^{10}$, a large $\Phi_{\mathrm{B} . J V}$ of $1.17 \mathrm{eV}$, and a close-to-unity $n$ of 1.02, which are comparable and even better than the reported high performance $\mathrm{Ga}_{2} \mathrm{O}_{3}$ SBDs with noble metal Schottky contacts [8], [10]-[12], [22], [26], [27].

To better understand the high quality Schottky contact interface, $C-V$ measurement was performed and the results are plotted in Fig. 2(c) and (d). The built-in potential, $V_{\text {bi }}$, of $1.25 \mathrm{~V}$ and the background doping density in the depletion region, $N_{\text {depl }}$, of $1.69 \times 10^{18} \mathrm{~cm}^{-3}$ were obtained by linear fitting of the $C-V$ curve [23], as shown in Fig. 2(c) and Table I. This net donor concentration in the $\mathrm{Ga}_{2} \mathrm{O}_{3}$ extracted from the $C-V$ characteristic is in reasonable agreement with the value of $1.0 \times$ $10^{18} \mathrm{~cm}^{-3}$. The high doping limited the depletion region thickness to $29 \mathrm{~nm}$ at $0 \mathrm{~V}$ as shown in Fig. 2(d). The free charge density of the $\mathrm{Ga}_{2} \mathrm{O}_{3}$ layer estimated from the $R_{\mathrm{s}}$ value is $1.47 \times$ $10^{17} \mathrm{~cm}^{-3}$ by using an electron mobility of $90 \mathrm{~cm}^{2} / \mathrm{Vs}$ [28]. The $\mathrm{SnO}_{\mathrm{x}} / \mathrm{Ga}_{2} \mathrm{O}_{3} \mathrm{SBD}$ has a very low $N_{\text {dep }} / N_{\mathrm{e}}$ ratio of 11 , indicating very low defect density, and this agrees well with the close-to-unity $n$ of 1.02 . The Schottky barrier extracted from the $C-V$ characteristic, $\Phi_{\mathrm{B}, C V}, \quad$ is $1.34 \mathrm{eV}$ by using $\Phi_{B}=q V_{b i}+k T / q \ln \left(N_{c} / N_{e}\right)$ [29], where the last term describing the energy gap between the conduction band and Fermi level is deduced to be $0.09 \mathrm{eV}$, and the conduction band density of states $N_{\mathrm{c}}$ is $5.2 \times 10^{18} \mathrm{~cm}^{-3}$ [29]. A close agreement of $\Phi_{\mathrm{B}, J V}(1.17 \mathrm{eV})$ and $\Phi_{\mathrm{B}, C V}(1.34 \mathrm{eV})$ indicates that the $\mathrm{SnO}_{\mathrm{x}} / \mathrm{Ga}_{2} \mathrm{O}_{3}$ Schottky contact has relatively high uniformity.
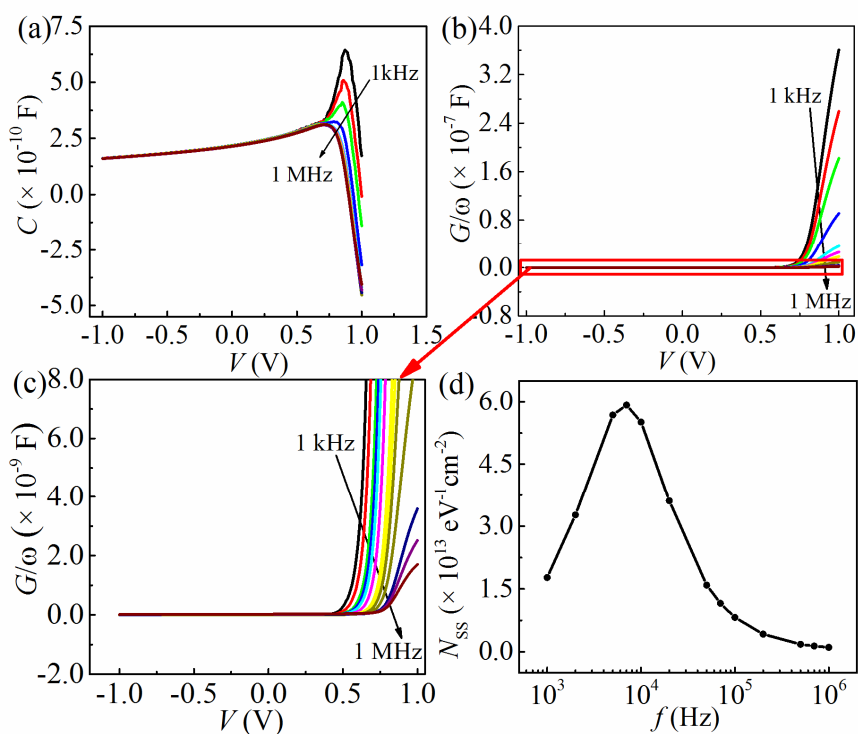

Fig. 3. Frequency dependence of (a) $C-V$ and (b) $G / \omega-V$ characteristics of the $\mathrm{SnO}_{\mathrm{x}} / \beta-\mathrm{Ga}_{2} \mathrm{O}_{3}$ SBD. (c) Partially enlarged view of $G / \omega-V$ curve. (d) Variation of $N_{\mathrm{ss}}$ as a function of the frequency.

To evaluate the $\mathrm{SnO}_{\mathrm{x}} / \mathrm{Ga}_{2} \mathrm{O}_{3}$ interface state density, the dependences of $C-V$ and conductance-voltage $(G / \omega-V)$ characteristics of the diode on the applied frequencies $(1,3,5,7$, $10,30,50,70,100,300,500,700,1000 \mathrm{kHz}$ ) were investigated, as shown in Fig. 3(a) - (c). Here, $\omega=2 \pi f$ is the angular frequency, and $G$ is the conductance. The value of $C$ increased slightly with increasing applied bias voltage firstly due to the decreasing depletion width, and then showed an anomalous peak at about $0.8 \mathrm{~V}$ due to the switching on of the diode, indicated also by Fig. 2(b) [30], [31]. This peak shows a decrease in value and a shift toward negative biases in position with increasing frequency. Such behavior is mainly due to the presence of interface states with various lifetimes [30], [31]. At low frequencies, the trap and de-trap of charges can follow the ac signal, and thus the charges at traps can contribute as excess capacitance to the measured capacitance $\left(C_{\mathrm{m}}\right)$. At high frequencies with voltage operation speed faster than the charge trap and de-trap speed, the charges at traps cannot contribute to the $C_{\mathrm{m}}$ any more. Figure 3(b) and (c) shows that under positive bias $(\sim 0.75-1 \mathrm{~V})$, the conductance increases slowly down with the increase of frequency, indicating the existence of interface states with different response time, and this is in good coordinate with the frequency dependent $C$.

Frequency dependence of interface state density, $N_{\mathrm{ss}}$, distribution was obtained by using Hill-Coleman method [32]. According to this method, the value of $N_{\text {ss }}$ can be determined from $C$ and $G / \omega$ values for each frequency as following [32],

$$
N_{S S}=\frac{2}{q A} \frac{(G / \omega)_{m}}{\left((G / \omega)_{m} / C_{i}\right)^{2}+\left(1-C_{m} / C_{i}\right)^{2}}
$$

here, $\omega=2 \pi f$ is the angular frequency, $C_{\mathrm{m}}$ is the peak value of the measured capacitance, and $G$ is the conductance corresponding to $C_{\mathrm{m}}$. $C_{\mathrm{i}}$ given by $C_{i}=C_{m}\left[1+\left(G_{m} / \omega C_{m}\right)^{2}\right]$ is the capacitance of the insulating interfacial $\mathrm{Ga}_{2} \mathrm{O}_{3}$ layer in strong accumulation at high frequency $(1 \mathrm{MHz})$, and the value of $C_{\mathrm{i}}$ is $27 \mathrm{nF}$. The value of $N_{\mathrm{ss}}$ determined by Eq. (1) is shown in Fig. $3(\mathrm{~d})$. The $N_{\mathrm{ss}}-f$ plot shows a peak and indicates that the activated $N_{\text {ss }}$ reaches a maximum of $5.92 \times 10^{13}$ at $7 \mathrm{kHz}$.

TABLE I

Characteristics of The SbD From $J V$ and $C V$ Measurements

\begin{tabular}{cccccccc}
\hline \hline $\begin{array}{c}\Phi_{\text {B. } . V} \\
(\mathrm{eV})\end{array}$ & $n$ & $\begin{array}{c}R_{\mathrm{S}} \\
\left(\mathrm{m} \Omega \mathrm{cm}^{2}\right)\end{array}$ & $I_{\text {on } / \text { off }}$ & $\begin{array}{c}N_{\mathrm{e}} \\
\left(\mathrm{cm}^{-3}\right)\end{array}$ & $\begin{array}{c}q \mathrm{~V}_{\text {bi }} \\
(\mathrm{eV})\end{array}$ & $\begin{array}{c}N_{\text {depl }} \\
\left(\mathrm{cm}^{-3}\right)\end{array}$ & $\begin{array}{c}\Phi_{\text {B. } . V} \\
(\mathrm{eV})\end{array}$ \\
\hline 1.17 & 1.02 & 28 & $>10^{10}$ & $1.47 \times 10^{17}$ & 1.25 & $1.69 \times 10^{18}$ & 1.34 \\
\hline \hline
\end{tabular}

\section{CONCLUSION}

In summary, a high performance $\beta-\mathrm{Ga}_{2} \mathrm{O}_{3}$ Schottky diode was fabricated using $\mathrm{SnO}_{x}$ as Schottky contact. The $\mathrm{SnO}_{x}$ film contains three components: $\mathrm{Sn}, \mathrm{SnO}$, and $\mathrm{SnO}_{2}$, of which $\mathrm{SnO}$ is the main component. The ultra-high quality Schottky contact interface was indicated by a near-unity ideality factor of 1.02 , a large barrier height of $1.17 \mathrm{eV}$, and a high on/off ratio of $>10^{10}$. This was achieved by that tin vacancies with oxygen dangling bonds in $\mathrm{SnO}$ compensate for oxygen vacancies in $\mathrm{Ga}_{2} \mathrm{O}_{3}$ at the Schottky interface and reduce the interface state density. The maximum active interface state density obtained by Hill-Coleman method is $5.92 \times 10^{13} \mathrm{eV}^{-1} \mathrm{~cm}^{-2}$. The high-performance $\mathrm{SnO}_{\mathrm{x}} / \mathrm{Ga}_{2} \mathrm{O}_{3}$ diode shows that $\mathrm{SnO}_{\mathrm{x}}$ film can be an excellent Schottky contact, which is inexpensive and convenient to deposit.

\section{REFERENCES}

[1] T. Onuma, S. Saito, K. Sasaki, T. Masui, T. Yamaguchi, T. Honda, M. Higashiwaki, "Valence band ordering in $\beta-\mathrm{Ga}_{2} \mathrm{O}_{3}$ studied by polarized transmittance and reflectance spectroscopy", Japan. J. Appl. Phys., Vol. 54, No. 11, pp. 112601, Oct. 2015. DOI: 10.7567/JJAP.54.112601 
[2] M. Higashiwaki, K. Sasaki, A. Kuramata, T. Masui, and S. Yamakoshi, "Gallium oxide $\left(\mathrm{Ga}_{2} \mathrm{O}_{3}\right)$ metal-semiconductor field-effect transistors on single-crystal $\beta-\mathrm{Ga}_{2} \mathrm{O}_{3}$ (010) substrates", Appl. Phys. Lett., Vol. 100, No. 1, pp. 013504, Jan. 2012. DOI: 10.1063/1.3674287

[3] H. He, R. Orlando, M. A. Blanco, R. Pandey, E. Amzallag, I. Baraille, M. Rerat, "First-principles study of the structural, electronic, and optical properties of $\mathrm{Ga}_{2} \mathrm{O}_{3}$ in its monoclinic and hexagonal phases", Phys. Rev. $B$, Vol. 74, No. 19, pp. 195123, Nov. 2006. DOI: 10.1103/PhysRevB.74.195123

[4] W. Y. Kong, G. A. Wu, K. Y. Wang, T. F. Zhang, Y. F. Zou, D. D. Wang, L. B. Luo, "Graphene- $\beta-\mathrm{Ga}_{2} \mathrm{O}_{3}$ Heterojunction for Highly Sensitive Deep UV Photodetector Application", Adv. Mat., Vol. 28, No. 48, pp. 10725-10731, Oct. 2016. DOI: 10.1002/adma.201604049

[5] T. P. Chow, I. Omura, M. Higashiwaki, H. Kawarada, V. Pala, "Smart Power Devices and ICs Using GaAs and Wide and Extreme Bandgap Semiconductors", IEEE Trans. Electron Devices, Vol. 64, No. 3, pp. 856-873, Feb. 2017. DOI: 10.1109/TED.2017.2653759

[6] Q. He, W. Mu, B. Fu, Z. Jia, S. Long, Z. Yu, Z. Yao, W. Wang, H. Dong, Y. Qin, G. Jian, H. Xue, H. Lv, Q. Liu, M. Tang, X. Tao, M. Liu, "Schottky Barrier Rectifier Based on (100) $\beta-\mathrm{Ga}_{2} \mathrm{O}_{3}$ and its DC and AC Characteristics", IEEE Electron Device Lett., Vol. 39, No. 4, pp. 556-559, Mar. 2018. DOI: 10.1109/LED.2018.2810858

[7] Z. Hu, H. Zhou, Q. Feng, J. Zhang, C. Zhang, K. Dang, Y. Cai, Z. Feng, Y. Gao, X. Kang, Y. Hao, "Field-Plated Lateral $\beta-\mathrm{Ga}_{2} \mathrm{O}_{3}$ Schottky Barrier Diode with High Reverse Blocking Voltage of More Than $3 \mathrm{kV}$ and High DC Power Figure-of-Merit of $500 \mathrm{MW} / \mathrm{cm}^{2}$ ". IEEE Electron Device Lett., Vol. 39, No. 10, pp. 1564-1567, Sep. 2018. DOI: 10.1109/LED.2018.2868444

[8] T. Watahiki, Y. Yuda, A. Furukawa, M. Yamamuka, Y. Takiguchi, S. Miyajima, "Heterojunction $\mathrm{p}-\mathrm{Cu}_{2} \mathrm{O} / \mathrm{n}-\mathrm{Ga}_{2} \mathrm{O}_{3}$ diode with high breakdown voltage", Appl. Phys. Lett., Vol. 111, No. 22, pp. 222104, Nov. 2017, DOI: 10.1063/1.4998311

[9] K. Konishi, K. Goto, H. Murakami, Y. Kumagai, A. Kuramata, S. Yamakoshi, M. Higashiwaki, "1-kV vertical $\mathrm{Ga}_{2} \mathrm{O}_{3}$ field-plated Schottky barrier diodes" Appl. Phys. Lett., Vol. 110, No. 10, pp. 103506, Mar. 2017.DOI: $\underline{10.1063 / 1.4977857}$

[10] K. Sasaki, D. Wakimoto, Q. T. Thieu, Y. Koishikawa, A. Kuramata, M. Higashiwaki, S. Yamakoshi, "First Demonstration of $\mathrm{Ga}_{2} \mathrm{O}_{3}$ Trench MOS-Type Schottky Barrier Diodes", IEEE Electron Device Lett., Vol. 38, No. 6, pp. 783-785, Apr. 2017. DOI: 10.1109/LED.2017.2696986

[11] S. Müller, H. von Wenckstern, F. Schmidt, D. Splith, F. L. Schein, H. Frenzel, M. Grundmann, "Comparison of Schottky contacts on $\beta$-gallium oxide thin films and bulk crystals", Appl. Phys. Express, Vol. 8, No. 12, pp. 121102-1-121102-4, Nov. 2015. DOI: 10.7567/APEX.8.121102

[12] J. Yang, S. Ahn, F. Ren, S. J. Pearton, S. Jang, J. Kim, A. Kuramata, "High reverse breakdown voltage Schottky rectifiers without edge termination on $\mathrm{Ga}_{2} \mathrm{O}_{3}$ ", Appl. Phys. Lett., Vol. 110, No. 19, pp. 192101-1-192101-4, Apr. 2017. DOI: 10.1063/1.4983203

[13] Q. He, W. Mu, H. Dong, S. Long, Z. Jia, H. Lv, Q. Liu, M. Tang, X. Tao, M. Liu, "Schottky barrier diode based on $\beta-\mathrm{Ga}_{2} \mathrm{O}_{3}(100)$ single crystal substrate and its temperature-dependent electrical characteristics.", Appl. Phys. Lett., Vol. 110, No. 9, pp. 093503, Mar. 2017. DOI: 10.1063/1.4977766

[14] M. W. Allen, S. M. Durbin, J. B. Metson, "Silver oxide Schottky contacts on n-type ZnO", Appl. Phys. Lett., Vol. 91, No. 5, pp. 053512, Jul. 2007. DOI: $10.1063 / 1.2768028$

[15] J. Zhang, Q. Xin, A. Song, "High performance Schotky diodes based on indium-gallium-zinc-oxide", J. Vac. Sci. Technol. A, Vol. 34, No. 4, pp. 04C101, Apr. 2016. DOI: 10.1116/1.4945102

[16] L. Du, J. Zhang, Y. Li, M. Xu, Q. Wang, A. Song, Q. Xin, "High-Performance Flexible Schottky Diodes Based on Sputtered InGaZnO”, IEEE Trans. Electron Devices, Vol. 99, pp. 4326 - 4333, Oct. 2018. DOI: 10.1109/TED.2018.2864165

[17] J. Kaczmarski, M. A. Borysiewicz, K. Piskorski, M. Wzorek, M. Kozubal, E. Kamińska, "Flexible IGZO Schottky diodes on paper", Semicond. Sci. Tech., Vol. 33, No. 1, pp. 015010, Nov. 2017. DOI: 10.1088/1361-6641/aa9acb

[18] J. Kaczmarski, J. Grochowski, E. Kamińska, A. Taube, M. A. Borysiewicz, K. Pągowska, W. Jung, A. Piotrowska, "Enhancement of $\mathrm{Ru}-\mathrm{Si}-\mathrm{O} / \mathrm{In}-\mathrm{Ga}-\mathrm{Zn}-\mathrm{O}$ MESFET performance by reducing depletion region trap density", IEEE Electron Device Lett., Vol. 36, No. 5, pp. 469-471, Mar. 2015. DOI: 10.1109/LED.2015.2411749

[19] R. Rao, A. M. Rao, B. Xu, J. Dong, S. Sharma, M. K. Sunkara, "Blueshifted Raman scattering and its correlation with the [110] growth direction in gallium oxide nanowires", J. Appl. Phys., Vol. 98, No. 9, pp. 094312, Nov. 2005. DOI: $10.1063 / 1.2128044$

[20] S. Kumar, S. Dhara, R. Agarwal, R. Singh, "Study of photoconduction properties of CVD grown $\beta-\mathrm{Ga}_{2} \mathrm{O}_{3}$ nanowires", J. Alloys Compounds, Vol. 683, pp. 143-148, Oct. 2016. DOI: 10.1016/j.jallcom.2016.05.079

[21] H. Luo, L. Y. Liang, H. T. Cao, Z. M. Liu, F. Zhuge, "Structural, Chemical, Optical, and Electrical Evolution of $\mathrm{SnO}_{\mathrm{x}}$ Films Deposited by Reactive rf Magnetron Sputtering", ACS appl. Mater. Inter., Vol. 4, No. 10, pp. 5673-5677, Oct. 2012. DOI: 10.1021/am301601s

[22] K. Sasaki, M. Higashiwaki, A. Kuramata, T. Masui, S. Yamakoshi, "Schottky Barrier Diodes Fabricated by Using Single-Crystal $\beta-\mathrm{Ga}_{2} \mathrm{O}_{3}$ (010) Substrates", IEEE Electron Device Lett., Vol. 34, No. 4, pp. 493-495, Mar. 2013. DOI: 10.1109/LED.2013.2244057.

[23] S. M. Sze and K. K. Ng, Physics of Semiconductor Devices, 3rd ed. New York: Wiley, 2007.

[24] Y. Li, Q. Xin, L. Du, Y. Qu, H. Li, X. Kong, Q. Wang, A. Song, "Extremely Sensitive Dependence of $\mathrm{SnO}_{\mathrm{x}}$ Film Properties on Sputtering Power", Sci. Rep., 6, 36183, Nov. 2016. DOI: 10.1038/srep36183

[25] A. Togo, F. Oba, I. Tanaka, K. Tatsumi, "First-principles calculations of native defects in tin monoxide", Phys. Rev. B: Condens. Mater, Vol. 74, No. 19, pp. 195128. Nov. 2006. DOI: 10.1103/PhysRevB.74.195128

[26] C. Joishi, S. Rafique, Z. Xia, L. Han, S. Krishnamoorthy, Y. Zhang, S. Lodha, H. Zhao, S. Rajan, "Low-pressure CVD-grown $\beta-\mathrm{Ga}_{2} \mathrm{O}_{3}$ bevel-field-plated Schottky barrier diodes", Appl. Phys. Express, Vol. 11, No. 3, pp. 031101, Feb. 2018. DOI: 10.7567/APEX.11.031101

[27] A. Jayawardena, A. C. Ahyi, S. Dhar, "Analysis of temperature dependent forward characteristics of $\mathrm{Ni} / \mathrm{\beta}-\mathrm{Ga}_{2} \mathrm{O}_{3}$ Schottky diodes", Semicond. Sci. Tech. Vol. 31, No. 11, pp. 115002, Sep. 2016. DOI:10.1088/0268-1242/31/11/115002

[28] Q. Xin, L. Yan, Y. Luo, A. Song, "Study of breakdown voltage of indium-gallium-zinc-oxide-based Schottky diode", Appl. Phys. Lett., Vol. 106, No. 11, pp. 113506, Mar. 2015. DOI: 10.1063/1.4916030

[29] L. Du, H. Li, L. Yan, J. Zhang, Q. Xin, Q. Wang, A. Song, "Effects of substrate and anode metal annealing on InGaZnO Schottky diodes", Appl. Phys. Lett., Vol. 110, No. 1, pp. 011602, Jan. 2017. DOI: $10.1063 / 1.4973693$

[30] Ç. Bilkan, A. Gümüş, Ş. Altındal, "The source of negative capacitance and anomalous peak in the forward bias capacitance-voltage in $\mathrm{Cr} / \mathrm{p}$-si Schottky barrier diodes (SBDs)", Mat. Sci. Semicon. Proc., Vol. 39, pp. 484-491, Nov. 2015. DOI: 10.1016/j.mssp.2015.05.044

[31] Ş. Karataş, A. Türüt, "The determination of electronic and interface state density distributions of Au/n-type GaAs Schottky barrier diodes" Physica B: Condens. Matter, Vol. 381, No. 1-2, pp. 199-203, May. 2006. DOI: 10.1016/j.physb.2006.01.412

[32] W. A. Hill, C. C. Coleman, "A single-frequency approximation for interface-state density determination", Solid State Electron., Vol. 23, No. 9, pp. 987-993, Sep. 1980. DOI: 10.1016/0038-1101(80)90064-7 